\title{
UMA ABORDAGEM CRÍTICA SOBRE A ORALIDADE E A ESCRITA NO CANDOMBLÉ DA BAHIA
}

CASTILLO, Lisa Earl. Entre a oralidade e a escrita: a etnografia nos candomblés da Bahia. Salvador: Edufba, 2008. 231p.

$A$ produção de textos e material fotográfico sobre o candomblé e outras denominações das heranças religiosas africanas reinterpretadas no Brasil é, hoje, bastante representativa no contexto editorial brasileiro. Os primeiros escritos datam do final do século XIX e resultam das pesquisas feitas na Bahia pelo médico maranhense Raimundo Nina Rodrigues. Desde 1896, com publicação de " $O$ animismo fetichista dos negros bahianos", até nossos dias, o candomblé da Bahia, nas suas diversas nações, foi tematizado em textos etnográficos produzidos no campo acadêmico e também em publicações de sacerdotes-autores. A publicação pela editora da Universidade Federal da Bahia da tese de doutorado de Lisa Earl Castillo inscrevese nesse cenário editorial.

O livro articula o campo da multidisciplinaridade, envolvendo estudos literários, antropologia, história, fotografia e, sobretudo, a epistemologia foucaultiana. Ancorada na vasta produção escrita sobre o candom- blé, a autora não se dá por satisfeita, nem mesmo com informações que vêm sendo reproduzidas ao longo de décadas, sem uma análise dos documentos e fatos históricos. Assim, seu afã investigativo analisa acontecimentos da época e questiona o presumido encontro entre a ialorixá fundadora do Ilê Axé Opô Afonjá e o presidente Getúlio Vargas no ano de 1937 (p.132-3). No entanto, essa não foi a sua principal indagação, e resposta, sobre o candomblé. Mesmo porque seu objetivo na pesquisa foi estabelecido a partir de indagações de uma mãe de santo, a quem ela agradece por lhe haver "incentivado a refletir sobre a dinâmica entre a academia e o terreiro" (p.7).

Contrariando uma tese frequentemente defendida no mundo acadêmico e também entre sacerdotes e pessoas dos candomblés, de que "o universo dos terreiros é um espaço exclusivo da oralidade" (p.11), a autora apresenta os usos êmicos da escrita, desde aqueles presentes nos chamados 
"cadernos de fundamento" até as faixas de ogãs e equedes e inscrições religiosas e informativas no interior dos terreiros, para demonstrar o lugar da escrita nos terreiros de candomblé. Entre os teóricos em que se apoia encontra-se Michel de Certeau, que compreende como dialética a relação entre oralidade e escrita, pares cujas posições não são fixas, mas relativas. Com base nesse aporte, emerge uma combinação instável e flutuante entre esses pares nos terreiros de candomblé.

O livro está organizado em quatro capítulos, além de introdução e conclusão. Nos anexos encontram-se ilustrações de textos manuscritos, jornais antigos, fotos que registram momentos e personalidades importantes, como aquele em que Jean-Paul Sartre e Simone de Beauvoir visitam Mãe Senhora no Ilê Axé Opô Afonjá, acompanhados de Jorge Amado e Zélia Gattai. A reprodução na capa do livro de uma fotografia do babalaô Martiniano do Bonfim, feita pela antropóloga Ruth Landes na década de 1930, expressa uma posição da autora não apenas com relação ao lugar da escrita no candomblé, mas também ao papel desempenhado por homens dentro dos terreiros. A foto retrata um imponente senhor septuagenário que, além de informante principal de Nina Rodrigues, também teve grande influência no estabelecimento e na organização de rituais em terreiros da Bahia.

$\mathrm{Na}$ introdução, a autora informa que, inicialmente, pensou em se concentrar nas narrativas etnográficas sobre o universo religioso afro-brasileiro. No entanto, ampliou essa perspectiva para comparar "os usos de fora" com os "usos de dentro", tanto da escrita como da fotografia. Ela anuncia que pretende demonstrar a existência de uma falsa dicotomia entre oralidade e escrita no candomblé. Além da pesquisa documental realizada nos arquivos de Salvador, seus dados foram obtidos não apenas nos terreiros mais conhecidos e antigos dessa cidade, mas também em outros mais novos.

Um breve resumo das discussões teóricas do campo da antropologia, envolvendo autores estrangeiros como Roger Bastide, Herskovits, Lévi-Strauss, Clifford, Geertz, e também brasileiros como Edison Carneiro, Beatriz Dantas, é apresentado na introdução como forma de explicitar "a oposição antropológica entre pureza e contaminação" (p.15), ou seja, como "alguns terreiros tiveram mais sucesso no processo de legitimar-se socialmente através da visibilidade etnográfica, exaltando as práticas puras e religiosas e rejeitando [...] as consideradas impuras" (p.17). Diante desse debate, a autora não se coloca em posição de neutralidade e nem considera neutras a etnografias produzidas sobre os candomblés da Bahia. Seu amparo é o argumento de James Clifford de que "por ser construída através de processo interpre- 
tativo do pesquisador, a etnografia é sempre marcada pela subjetividade do estudioso" (p. 20).

No primeiro capítulo a autora discorre sobre "o quadro epistemológico: a transmissão do saber e o segredo". Nele comparecem os estudos que consideram a oralidade como oposta à escrita e via exclusiva de transmissão do saber nos terreiros. Dentre esses estudos, ela se refere especialmente a autores como Juana Elbein dos Santos e Pierre Verger. O problema sobre o uso de registros escritos e visuais no candomblé é compreendido como uma transgressão dos "limites de um corpo de conhecimento de circulação restrita aos chamados fundamentos religiosos, também popularmente conhecidos como 'o segredo"” (p.25). Tais fundamentos têm acessos controlados e sua transmissão obedece ao princípio da senioridade iniciática. No entanto, conforme observou a autora, as restrições estão relacionadas às disputas de poder e prestígio no interior dos terreiros, e entre terreiros e a sociedade.

Após abordar o significado da oralidade e do segredo no candomblé, nesse primeiro capítulo, a autora recorre aos estudos de Paul Christopher Johnson que afirma que

"tudo o que poderia ser considerado fundamentos religiosos no candomblé já foi publicado, deixando apenas instâncias idiossincráticas de magia individual... [as quais] não são religiosas no sentido de um conhecimento sistemático [...]" (p.46)

Johnson qualifica como "ideologia do segredo" essa "prática de guardar o acesso a corpo delimitado de conhecimentos" e cria o termo "secretismo" para abordar como o poder do segredo cresce, independente de existir ou não, através da circulação de sua inacessibilidade. (p.46). Conforme Johnson, "o segredo tornou-se simplesmente um blefe, um ar ostensivo cujo único fim é despertar a curiosidade do interlocutor." (p.46). No entanto, conforme a perspectiva de Muniz Sodré, no segredo nagô, aquilo que é dito não tem poder para acabar com o mistério que pertence às regras do jogo cósmico. Com efeito, se vamos compreender o segredo na perspectiva de um mistério, teremos de aceitar que a sua transmissão não se dá nem pela oralidade nem pela escrita, posto que é inefável e insondável.

No segundo capítulo a autora tematiza o eixo central de sua tese, "Os "entrelugares" da oralidade: usos êmicos da escrita e da fotografia", através do exame de artigos e fotografia no candomblé (p.57). A partir da sua principal base epistemológica, a etnografia é considerada na perspectiva de Foucault como um nó em uma rede de práticas discursivas. Em seu entendimento, às narrativas etnográficas acrescentam-se outras do tipo jornalísticas e literárias, em que as 
práticas discursivas da sociedade externa são influenciadas palas práticas preexistentes no terreiro. Isso significa dizer que os discursos produzidos no interior dos terreiros, pelos sujeitos do culto, influenciaram e influenciam as narrativas etnográficas, tanto do ponto de vista da escrita quanto da fotografia.

Ao argumento que celebra a existência de uma civilização oral, a autora contrapõe uma reflexão sobre o fato de que antropologia tinha como base a teoria evolucionista que apresentava as sociedades sem escrita como primitivas em contraposição às sociedades letradas, como avançadas. Remetendo-se aos estudos de Johannes Fabian, que se constituem como uma crítica à epistemologia hegeliana, a autora registra que "essa ideia levou ao pressuposto de que sem um registro escrito, uma perspectiva histórica era impossível, e as culturas ágrafas eram representadas como se fossem congeladas no tempo" (p.58).

O resultado desses aportes problemáticos da antropologia evolucionista é apontado como uma "tendência etnográfica a desconhecer a existência de práticas envolvendo a escrita nos terreiros de candomblé" (p.58). Essa tendência resultou em juízos depreciativos imputados aos sujeitos do culto que utilizavam a escrita. Assim, em sua obra "A cidade das mulheres", Ruth Landes associa o uso da escrita no terreiro de Sabina, como sendo vincula- do "a perda da autenticidade africana, a degradação ritual (simbolizadas pelas práticas ligadas aos caboclos) a ambição e o charlatanismo" (p.59). Aqui vale a ressalva de que Ruth Landes elabora as posições depreciativas de Mãe Menininha e de Martiniano do Bonfim sobre as práticas do candomblé da sacerdotisa Sabina. Tais elaborações sinalizam práticas discursivas preexistentes no interior dos terreiros influenciando uma etnografia. Para usar um termo afeto à perspectiva de Geertz, do ponto de vista metodológico, trata-se de uma falta de distinção entre o discurso do nativo e o discurso do antropólogo.

Uma perspectiva diferenciada com relação à coexistência entre a oralidade e a escrita no candomblé é identificada na obra do antropólogo e pai de santo Júlio Braga, cuja reflexão, além de sugerir que essa dicotomia "parece vir de fora para dentro", identifica "uma visão exagerada da oralidade como único meio para a transmissão do saber religioso" (p.59). Como bom conhecedor das vivências do povo do santo, Júlio Braga reconhece as estratégias usadas para ampliar os conhecimentos mágicos religiosos. Com certeza, as distintas práticas rituais dos dois candomblés que têm a Casa Branca como origem tem a ver com as diversas estratégias usadas para configurar rituais compreendidos como puramente africanos. Nesse sentido, a ideia de que o uso da escrita no can- 
domblé seja uma deturpação da pureza nagô é afrontada por um texto do pai de santo Manoel Falefá, publicado nos anais do II Congresso AfroBrasileiro, em 1940, no qual ele sugere que o uso da escrita pela religiões de matriz africana antecede o contato com os europeus.

No terceiro capítulo, o subtítulo apresenta "Martiniano do Bonfim e a construção do discurso sobre o candomblé", analisando o período que vai da publicação de Nina Rodrigues, em 1896, até os anos de 1950, quando as obras de Roger Bastide e Pierre Verger projetaram o candomblé no cenário internacional. Os períodos, fatos e personalidades históricas analisados pela autora evidenciam duas questões: a primeira refere-se ao fato de que os estudos surgiram de "uma relação privilegiada entre estudiosos do candomblé e um pequeno número de terreiros prestigiados por sua antiguidade e pela manutenção de tradições consideradas mais puras [...]" (p.103). A segunda diz respeito ao fato de que "o envolvimento no discurso etnográfico surgiu da percepção do seu valor estratégico fora dos terreiros em possibilitar a disseminação de uma imagem mais favorável do candomblé perante a sociedade brasileira" (p. 143).

O primeiro estudioso colocado em foco é Nina Rodrigues, que em 1896 publicou sua monografia sobre " $O$ animismo fetichista e os negros bahianos" em que "descreveu detalha- damente crenças e rituais da religião dos orixás, com base em observações realizadas em vários terreiros de Salvador e pelo menos um do Recôncavo" (p. 103-4). Outro estudioso que se debruçou sobre as heranças religiosas africanas no Brasil foi Manoel Querino, que se destaca por rejeitar a posição de Nina Rodrigues sobre a inferioridade biológica dos negros. Embora a autora afirme que Manuel Querino não se posicionava como alguém que pertencia ao candomblé, o fato de ser ogã suspenso no terreiro do Gantois confirma um tipo de vínculo com uma comunidade religiosa.

A partir da década de 1930, o candomblé da Bahia ganhou novos estudos realizados por Arthur Ramos, outro médico, que defendeu a tese "Primitivo e Loucura", "cujo título reflete a influência das ideias evolucionistas da época" (p.115). Além de Arthur Ramos, os estudos de Edison Carneiro, Ruth Landes e os textos de sacerdotes e sacerdotisas, como Martiniano do Bomfim, Mãe Aninha, Bernardino do Bate Folha, Manuel Falefá, publicados nos anais do II Congresso Afro-Brasileiro, em 1940, formam um conjunto de textos que não apenas evidenciaram o candomblé da Bahia para o mundo, como também se constituíram em discursos estratégicos para o combate à perseguição policial aos terreiros, desencadeada na década de 1920. Nesse contexto, o pai de santo Joãozinho da Gomeia, com 
apenas 24 anos de idade, mesmo sendo hostilizado pelos tradicionalistas, aproveitou a oportunidade do II Congresso em 1937, reivindicou o direito à liberdade religiosa e denunciou, em uma entrevista ao jornal Estado da Bahia, o fato de os candomblés, religião de negro, terem de pagar uma taxa na Delegacia de Jogos e Costumes para poder realizar seus rituais, quando a Igreja Católica, principal representante da religião de branco, não pagava taxa nenhuma.

No quarto e último capítulo do livro sobre as "percepções contemporâneas: leitores e escritores nos terreiros", a autora assevera que "ao invés de refugiar-se na invisibilidade social como sua principal estratégia de sobrevivência, os terreiros passaram a se expor à visibilidade controlada como mecanismo de proteção" (p.147). Nessa perspectiva, o Opô Afonjá é considerado o terreiro que manteve o equilíbrio entre "transmissão tradicional do saber e o uso seletivo da escrita" (p.175). No entanto, reflexões e obras como a do sacerdote Altair de T'Ogun colocam em discussão a transmissão tradicional do saber. Além de T'Ogun, que opera com a transcrição em iorubá do conjunto de cânticos e de rituais do candomblé, a outra alternativa é a reafricanização da tradição religiosa dos orixás, cuja perspectiva é seguida pela ialorixá Sandra Epega em São Paulo, que se ressente da ausência de um corpo de doutrina como a do cristianismo (p.158).

Na conclusão, o carisma de determinados sacerdotes e as amizades pessoais comparecem como tendo contribuído muito para evidenciar alguns terreiros, assim como colocar a escrita como um instrumento de visibilidade e exposição pública dessas comunidades. A autora encerra seu texto sinalizando o fato de que ampliação do acesso à educação por parte das novas gerações do povo de santo, através de programas governamentais como bolsas escolas e cotas nas universidades públicas, apontam para um horizonte de "transformações no que tange a transmissão do saber religioso no candomblé" (p.190).

Na condição de sujeito do culto, sacerdote-autor e intelectual vinculado às questões da militância negra $\mathrm{e}$ religiosa, considero a pesquisa de Lisa Earl Castillo uma contribuição importante para o debate sobre a relação entre oralidade e escrita no candomblé, muitas vezes tratada numa perspectiva maniqueísta. Em todo o seu percurso de investigação junto ao povo de santo, salta aos olhos a pergunta sobre a possibilidade da existência de recursos de memória suficientes para a manutenção das religiões brasileiras de matrizes africanas pelas novas gerações. Isso porque, a juventude do candomblé, bem diferente das gerações passadas, além de avançar no processo de escolarização, interage com 
outros estilos de vida e visões de mundo bem distintos daqueles das gerações que tiveram de lutar tanto contra uma visão negativa sobre o candomblé quanto contra a perseguição e invasão da polícia aos terreiros, em uma época em que seus templos religiosos tinham de ser registrados na Delegacia de Jogos e Costumes. Vale ressaltar que, na atualidade, muitos membros das novas gerações do candomblé estão correspondendo às expectativas da ialorixá fundadora do Ilê Axé Opô Afonjá: "com anel de doutor nos dedos, aos pés de Xangô" (p.19)

De fato, retirando fora as idiossincrásicas perspectivas de magias individuais e um repertório de cânticos e rezas, muitas vezes contendo palavras inaudíveis, presentes no acervo da memória de alguns/mas pais e mães de santo, os rituais, as rezas, os assentamentos, os cânticos, as danças, as práticas gestuais, a culinária, as indumentárias e as disposições de espaço dos templos religiosos encontramse registrados, seja em textos etnográficos ou para-etnográficos. Portanto, a escrita não pode transgredir 'segredos' que não existem mais. A reivindicação de exclusividade de um tipo de transmissão considerada tradicional não se sustenta diante da falta dos mesmos recursos de memória dos antigos, da diversificação de práticas e da complexidade da vida cotidiana. Não há um tribunal que possa julgar e impedir a diversificação de saberes e aprendiza- gens. Aliás, o respaldo religioso e social adquiridos pelo pai de santo Joãozinho da Gomeia, após ter sido julgado e desqualificado por etnografias e sacerdotes vinculados a uma perspectiva de tradição, retratam bem o fato de que não é apenas entre o céu e a terra que existem muitas coisas que a vã filosofia não consegue explicar, mas também entre o deslocamento forçado de africanos para o Brasil e rituais e práticas religiosas aqui reinterpretadas, existem muito mais coisas do que se pode transmitir, tanto através da oralidade quanto pela escrita.

Não é este o foco da autora, mas há uma pesquisa que historiadores e etnógrafos estão nos devendo, a fim de oferecer aportes críticos sobre a dinâmica entre a academia e o candomblé. Refiro-me aos motivos que explicam a fama do Seu João da Pedra Preta, bem como de outros sacerdotes que desde o século XIX vêm exercendo o comando nas religiões brasileiras de matrizes africanas, pois questionam não apenas o tipo de etnografia homofóbica de "A cidade da mulheres", mas a todas as posições que advogam em favor da primazia e exclusividade das mulheres no sacerdócio das religiões brasileiras de matrizes africanas. Afinal, Ruth Landes não afirmou que "é quase tão difícil que um homem chegue a ter renome no candomblé quanto parir" (p.43)?

Erisvaldo Pereira dos Santos

Universidade Federal de Ouro Preto 